\title{
Rehabilitation of Children with Anorectal Malformations
}

\author{
TT Narbayev, U Kh Tilavov, NN Turaeva, BA Terebaev, FO Sobirova, JF Arifdjanova, ND Yuldasheva and MM Nasirov* \\ Tashkent Pediatric Medical Institute, Department of Pediatric Surgery, Uzbekistan
}

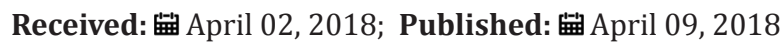

*Corresponding author: Mansur Nasirov, Tashkent Pediatric Medical Institute, Uzbekistan

\section{Introduction}

Rehabilitation of patients after anoplastic surgery is the most complex and poorly studied problem in the surgery of anorectal malformations. The process of rehabilitation should begin from the moment of diagnosis. Already in the earliest period, the question should be decided at what age a radical operation will be carried out. The second problem is always to determine the size of the outer opening of the ectopic anal canal. If the available opening is not sufficient for normal bowel evacuation, which is accompanied by signs of intestinal obstruction, this child should be given a colostomy, with which the patient will live until the moment of the radical surgery. In those cases where the external aperture of the ectopic anal canal allows unobstructed evacuation of the intestine before the radical surgery is performed, the colostomy should be applied as the first stage of multi-stage surgery. According to the literature, after surgical correction of the studied pathology in girls $40-60 \%$ of children suffer from incontinence of intestinal contents of various degrees, 27-38\% of children suffer from constipation (K. U. Ashcraft, T. M. Holder 1990, K. N. Salamov, U. V. Dultsev, 1998, A. I. Lenyushkin 2003, A. Pena 1988, A. M. Holschneider 1994, V. Aftimas 2001) [1].

According to most researchers, a good outcome, as well as a reduction in the number of complications, depends not only on the choice of surgical intervention method, but also on rehabilitation measures (A. I. Lenyushkin 1999, A. Pena 1993). Stool incontinence after surgical treatment of anorectal malformations is the most serious complication in the social aspect. The factors that lead to violation of the control of defecation are congenital and acquired during the operation, violations of the anatomical structure of the pelvic floor muscles and the external sphincter, as well as a violation of the sensitivity and proprioceptivity of the lowered intestine (F.D. Stephens and E.D. Smith, J.J. Templeton and J.A. Diteshim 1985). Rehabilitation of children with low anorectal malformation should take place during all stages of their examination and surgical treatment. The operation in turn is only a stage in the complex treatment of children with malformations of the anorectal region [2]. The right choice and perfect execution, the absence of postoperative complications, will undoubtedly contribute to the obtaining of good functional results, but the final result will be determined to a greater extent by the quality of rehabilitation measures in the near and distant postoperative period.

Rehabilitation measures should be carried out without interruption until the new rectum formed normal function.

\section{The objectives of rehabilitation are:}

a. prevention of development of cicatricial deformation of the anus and rectum;

b. instilling in the child the skill of an independent act of defecation;

c. psychomotor stimulation of restoring the function of confinement.

Purpose of the study is improvement of the results of treatment of children with anorectal malformations by performing stage-bystage rehabilitation treatment [3].

\section{Material and Methods}

All children received admission along with general clinical examination methods: fistulo-urigraphy, excretory urography, cystography, perineal ultrasound (pelvis), sphincterometry, measurement of pressure in the ampulla of the rectum, morphological studies of the distal parts of the rectum and sphincter apparatus. The immediate and long-term results of surgical treatment of 102 children with anorectal malformations were studied. Long-term results were studied in 86 (85\%) operated. Good results were obtained in 54 (62.8\%), satisfactory in 25 (29\%) and unsatisfactory - in 7 (8.2\%).

\section{Results and Discussion}

One of the complex tasks of rehabilitation of children with anorectal malformation is the development of their skills of an 
independent act of defecation. This is a very complex reflex process under normal conditions with a normal anatomical structure of the pelvic bones, pelvic floor muscles and the rectum with its sphincter apparatus. With atresia of the anal opening and ectopia of the anal canal in the vestibule of the vagina or in the perineum after the anal canal is re-implanted into the external sphincter, naturally, not only anatomical deviations from the norm, but also reflex-functional ones take place [4]. In these conditions it is necessary to "teach" the rectum to function normally, it is necessary to form reflex mechanisms of defecation with regular evacuation of the intestine. After engraftment of the rectum, which was reduced in any way to the center of the external sphincter of the rectum (2.5-3 weeks after the operation), gradual bougiement of the newly formed anal opening with Gegar dilators begins.

With this method of forming the anus, the muscles of the external sphincter and pelvic floor gradually stretch, but do not tear and do not overstrain. After the removal of the bougie, they again take the original form. From the moment when the anal opening starts to pass the nail phalanx of the index finger of the child's mother, the finger is bougaged with a constant desire to introduce it deeper to the proximal end of the main phalanx. This tactic helps to prevent the development of scar scarring. Along with this, there is a gradual expansion of the anal canal, as well as the formation of a reflex to the act of defecation. The development of cicatrical deformation of the anus is prevented by the constant bouginage with the help of expander Gegar or finger bougie. If before the closure of the colostomy the bougie is carried out 2-3 times a day for 3-5 minutes, then after its elimination - not less than 1 time per day. The duration of the bougie depends on the condition of the anal opening [5]. In cases when there are no signs of its stenosis, after 1-1.5 months it is possible to make control bouginage 1 time in 3-5 days for the same period, and then 3 times a month during the year. In the future, the issue is solved individually.
If the child has signs of scarring of the anal opening, daily bougie 2-3 times is carried out within 2-3 months. After that, within 1-1,5 months, the anus is bougied daily 1 time per day. 3-4.5 months after the beginning of bougie, it continues, but not more often 1-2 times a week for 2-3 months. Simultaneously with conduction of bougie of the anus, the child is given physiotherapy treatment. The child also undergoes training and cleansing enemas. For training enemas, we suggest using a $1 \%$ solution of common salt in a volume of 150-200 $\mathrm{ml}$ in warm form, depending on the age of the patient. This fluid is introduced into the rectum in such a volume, which causes irritation of the latter and a sense of the need for an act of defecation. After this, the child should try to keep the injected liquid as much as possible, and then remove it, producing an act of defecation. To develop a urge on the act of defecation, a 5\% solution of table salt should be used at room temperature. The introduction into the lumen of the rectum of such a solution causes the irritation and the urge for an act of defecation [6].

Enema should be done 2 times a day for 3-4 weeks at the same time: in the morning - training, in the evening - cleansing hypertonic. After each enema the child is planted on a pot or toilet bowl. At the end of the enema cycle, the child at the same time continues to be planted daily on the pot. At low atresia after minimally traumatic surgeries, this technique of reflex to the act of defecation gives a good effect. The effectiveness of ongoing rehabilitation measures was assessed according to sphincterometry. With each subsequent course of rehabilitation measures, these sphincterometrics improved, which gave hope for a good result in the long run. It should be noted that the indices of sphincterometry were directly proportional to the data of the questionnaire survey (Table 1). As can be seen from Table 1, an anal sphincter insufficiency, 1 girl (4.7\%) was followed by Stone-Benson's PPP and 8 children (21\%) after the PPP in the clinic modification. After the operation, ASARP and PSARP the anal sphincter insufficiency were not observed.

Table 1: Evaluation of long-term results according to sphincterometry (a year after surgery).

\begin{tabular}{|c|c|c|c|c|c|}
\hline Degree of anal sphincter insufficiency & $\begin{array}{l}\text { PPP by Stone Benson } \\
n=21\end{array}$ & PSARP $n=12$ & ASARP $n=16$ & $\begin{array}{c}\text { PPP in the modification of } \\
\text { the clinic } n=38\end{array}$ & Total \\
\hline $\begin{array}{l}\text { Without the insufficiency of the anal } \\
\text { sphincter }\end{array}$ & $\begin{array}{c}1 \\
(4,8 \%)\end{array}$ & - & - & $\begin{array}{c}8 \\
-21 \% \\
\end{array}$ & $\begin{array}{c}9 \\
(10,3 \%)\end{array}$ \\
\hline Insufficiency of 1 degree & $\begin{array}{c}5 \\
(23,8 \%)\end{array}$ & $\begin{array}{c}3 \\
-25 \%\end{array}$ & $\begin{array}{c}3 \\
(18,7 \%)\end{array}$ & $\begin{array}{c}19 \\
-50 \%\end{array}$ & $\begin{array}{c}30 \\
(34,5 \%)\end{array}$ \\
\hline Insufficiency of 2 degree & $\begin{array}{c}12 \\
(57,1 \%)\end{array}$ & $\begin{array}{c}5 \\
(41,6 \%)\end{array}$ & $\begin{array}{c}10 \\
(62,5 \%)\end{array}$ & $\begin{array}{c}11 \\
(28,9 \%)\end{array}$ & $\begin{array}{c}38 \\
(43,7 \%)\end{array}$ \\
\hline Insufficiency of 3 degree & $\begin{array}{c}3 \\
14,2 \%)\end{array}$ & $\begin{array}{c}4 \\
(33,3 \%)\end{array}$ & $\begin{array}{c}3 \\
(18,7 \%)\end{array}$ & - & $\begin{array}{c}10 \\
(11,5 \%)\end{array}$ \\
\hline
\end{tabular}

The greater number of children with first grade insufficiency nature of the operation, the elaboration of the reflex to the act of was followed after the operation of the PPP in the modification of the clinic (50\% of cases), which could be eliminated in the course of long-term rehabilitation treatment. Unfortunately, after lowering the rectum in the posterior-sagittal method, abdominal or abdominal-sacropromental method due to the large traumatic defecation is a more complex and not always successful procedure. Similar difficulties are observed in those children who have underdevelopment of the bones of the sacrum and coccyx. These patients have to re-conduct a course of training and cleansing enemas in 1-1.5 months. The elaboration of the reflex to the act of 
defecation should be carried out simultaneously in a single block with the training of anal holding. For this purpose, physiotherapeutic treatment is carried out in combination with various complexes of therapeutic physical training.

In order for it to be successful, the child must be psychologically prepared. He clearly should understand the inferiority of his rectum and retaining apparatus, the meaning of training exercises. Only in this situation will the child be able to properly perform the tasks offered to him. Rectal gymnastics for the elaboration of a holding reflex can be multifaceted. Buying after the formation of the anal opening of the rectum with low anorectal malformations, bougie is the beginning of rectal gymnastics. When the finger is baked with a finger, the child must learn to clearly identify the feeling of passing the finger in the pubic-rectum muscle and the muscles of the external sphincter, perform the commands of the bouginage: "pinch your finger," "relax." Training of the muscles of the sphincter apparatus can be carried out by inserting into the rectum a rubber tube, which the child must restrain, straining the muscles of the pelvic floor. During the session of training contractions and muscle Table 2: The protocol of postoperative rehabilitation. relaxations around the tube, you need to monitor the correctness of the commands.

The number of cuts and relaxations can reach 30-40 in one session. The child is taught to hold the tube in the rectum, not only in the supine position, but also in the vertical position. The retention reflex can also be produced with the help of a rubber cylinder, which after filling into the rectum is filled with air or liquid to a feeling of urging on the act of defecation. After this, the child must mimic the retention of the contents of the rectum, contracting the muscles of the pelvic floor. Simultaneously with the contraction of these muscles, special exercises are performed for the muscles of the abdominal and lower extremities. Based on the literature data and the results of our own observations, we developed a protocol for the rehabilitation treatment of children with anorektoplasty based on the correction of complications of the nearest postoperative period, regardless of the method of operation (Table 2). By the end of the first year of rehabilitation treatment, the volitional reduction of sphincter muscles increased by $27.2 \%$ and subsequently to $29 \%$ of the primary level $(\mathrm{p}<0.05)$.

\begin{tabular}{|c|c|c|c|c|c|}
\hline \multirow{2}{*}{$\begin{array}{l}\text { Method of rehabilitation } \\
\text { therapy }\end{array}$} & \multicolumn{5}{|c|}{ Duration of therapy } \\
\hline & 1-3 month & 3-6 month & 6-12 month & 1-1,5 year & More than 2 years \\
\hline $\begin{array}{c}\text { Bougienage with Gegara's } \\
\text { expander }\end{array}$ & $\begin{array}{l}\text { Starting from the 20th } \\
\text { day after surgery, daily }\end{array}$ & In 2-3 days & $\begin{array}{l}\text { Control bougienage } 1 \\
\text { time in } 2-3 \text { weeks }\end{array}$ & - & - \\
\hline $\begin{array}{c}\text { Finger massage of the anal } \\
\text { opening }\end{array}$ & After 20 days daily & Daily & In 2-3 days & Once a week & - \\
\hline $\begin{array}{l}\text { Electrostimulation of the } \\
\text { sphincter }\end{array}$ & 1 time in 2 months & 1 time in 2 months & Every 2 months & - & - \\
\hline $\begin{array}{l}\text { Training enemas. Start } \\
\text { with } 1 \% \mathrm{NaCl} \text { solution and } \\
\text { gradually bring up to } 5 \% \\
\text { solution ( } 2 \text { weeks) }\end{array}$ & - & - & Every 3 months & 2 times a year & 1 times a year \\
\hline $\begin{array}{c}\text { Cleansing enema (reflex } \\
\text { development) }\end{array}$ & daily & Morning enemas daily & $\begin{array}{c}\text { Every } 2 \text { months for } 2 \\
\text { weeks }\end{array}$ & 4 times a year & - \\
\hline Exercise therapy & - & 1 time in 2 months & 1 time in 2 months & 1 time in 2 months & 1 time in 2 months \\
\hline
\end{tabular}

At the same time in 3 children with an incompleteness of the anal sphincter of the 2nd degree there was an increase in the indices of volitional reduction by $33 \%$, which was equated with the indices of the 1 degree of insufficiency. When comparing the indices of sphincterometry in dynamics after classical methods of operations with PPP in the modification of the clinic, the difference was significant $(p<0.05$ ). Volitional reduction of sphincter muscles in children with the first degree of insufficiency in the dynamics increased by $13 \%$ in 1 year by $20.1 \%$ and after 2 years by $29.3 \%$. While in children with a 2 degree of insufficiency, there was no significant improvement in the indices. In the sphincterometric study, the most pronounced dynamics of the increase in the total contractility of the formed nonosfinkter was observed with an increase in the time after operative intervention. Dynamic control of sphincterometric data after a conservative therapy cycle after 2 years showed an increase in average values of volitional reduction by an average of $29.1 \%$, which could be a positive prognostic sign and confirmed clinical data and questionnaire data.
Based on the obtained data of sphincterometry and a questionnaire survey in dynamics, it can be said that as a result of successive rehabilitation measures for 1-2 years, the children have a positive dynamics. As can be seen from the results of sphincterometry in the dynamics and data of the evaluation scale, the holding according to Rinitala will be determined to a greater extent by the quality of rehabilitation measures in the near and distant postoperative period. Rehabilitation measures were carried out until the normal function of the formed anus was achieved (Table 3). At insufficiency of II degree (27 children) neoanus also was put in place of its natural location, but the power reduction is significantly weakened. The urge to persist was maintained, as was the conscious act of defecation, but the control of the stool was broken, there was considerable calomination with little physical exertion and even at rest, especially by the end of the day. In $55.1 \%$ of children, the incompleteness of the anal sphincter of the 2 nd degree, traced in the first 9-12 months, as a result of prolonged and systematic rehabilitation therapy, was reduced to 1 degree. 
Table 3: Change in sphincterometry in long-term treatment.

\begin{tabular}{|c|c|c|c|c|c|c|c|}
\hline \multirow{2}{*}{$\begin{array}{c}\text { PPP } \\
\text { methods }\end{array}$} & \multirow{2}{*}{$\begin{array}{l}\text { Insufficiency of } \\
\text { anal sphincter }\end{array}$} & \multicolumn{2}{|c|}{ In 6 months } & \multicolumn{2}{|r|}{ After 1 year } & \multicolumn{2}{|r|}{ After 3 years } \\
\hline & & Rest & volitional reduction & Rest & volitional reduction & Rest & volitional reduction \\
\hline \multirow{3}{*}{$\begin{array}{l}\text { PPP in the } \\
\text { modification } \\
\text { of the clinic }\end{array}$} & 1 degree $n=28$ & $25 \pm 0,65^{*}$ & $48 \pm 0,34$ & $25 \pm 0,58$ & $49 \pm 1,21$ & $25 \pm 1,31$ & $49 \pm 1,56$ \\
\hline & 2 degree $n=10$ & $19 \pm 1,91$ & $42 \pm 0,98$ & $23 \pm 1,2$ & $43 \pm 0,76$ & $23 \pm 1,3$ & $46 \pm 0,78$ \\
\hline & 3 degree $n=0$ & & & & & & \\
\hline \multirow{3}{*}{ PSARP } & 1 degree $n=6$ & $20 \pm 0,65^{*}$ & $36 \pm 0,23 *$ & $22 \pm 0,38^{*}$ & $42 \pm 0,87$ & $22 \pm 1,01$ & $45 \pm 1,09$ \\
\hline & 2 degree $n=4$ & $14 \pm 1,31$ & $29 \pm 1,08$ & $17 \pm 1,23$ & $30 \pm 0,76$ & $17 \pm 1,03$ & $30 \pm 0,68$ \\
\hline & 3 degree $n=2$ & $7,1 \pm 1,3$ & $15,5 \pm 0,5$ & $7,8 \pm 1,09$ & $15,4 \pm 0,6$ & $7,6 \pm 0,79$ & $15,6 \pm 0,7$ \\
\hline \multirow{3}{*}{ ASARP } & 1 degree $n=7$ & $21 \pm 1,06^{*}$ & $39 \pm 0,67$ & $22 \pm 0,68$ & $45 \pm 0,73$ & $22 \pm 1,11$ & $47 \pm 1,19$ \\
\hline & 2 degree $n=6$ & $13 \pm 1,33$ & $29 \pm 0,88$ & $18 \pm 1,33$ & $31 \pm 0,96$ & $20 \pm 1,23^{*}$ & $35 \pm 0,58$ \\
\hline & 3 degree $n=3$ & $7,1 \pm 1,08$ & $16,3 \pm 0,7$ & $8,2 \pm 1,19$ & $17,4 \pm 0,7$ & $9,6 \pm 0,92$ & $21,6 \pm 0,6$ \\
\hline \multirow{3}{*}{$\begin{array}{l}\text { PPP by Stone } \\
\text { Benson }\end{array}$} & 1 degree $n=14$ & $20 \pm 1,16^{*}$ & $39 \pm 1,07$ & $21 \pm 0,82$ & $42 \pm 0,73$ & $22 \pm 1,11^{*}$ & $48 \pm 1,19$ \\
\hline & 2 degree $n=5$ & $15 \pm 1,23$ & $27 \pm 1,11^{*}$ & $18 \pm 1,22$ & $31 \pm 1,06$ & $20 \pm 1,13$ & $32 \pm 1,18$ \\
\hline & 3 degree $n=2$ & $7,2 \pm 1,12$ & $17,1 \pm 0,8$ & $8,7 \pm 1,09$ & $18,4 \pm 0,5$ & $10 \pm 1,91$ & $22,6 \pm 0,7$ \\
\hline
\end{tabular}

A major role in the development of reflexes to urge for the act of defecation and retention is given to the activities of a therapeutic and educational nature, in which parents take an active part under the supervision of the doctor. The result of treatment largely depends on the mutual understanding of doctors and parents. Parents should know that the normal function in full for children, operated on the congenital malformation of the anorectal region and even with the underdevelopment of bone structures and pelvic floor muscles, is unattainable. Therefore, it is necessary to persevere in everything that the child can be socially adapted. For at least 3-5 years after the operation, all children operated on for malformations of the anorectal area should be on dispensary records under the supervision of pediatric surgeons who supervise and correct the rehabilitation activities. This contributes to the early detection of a number of complications, the timely conservative treatment of which prevents the need for repeated operations [6].

Proceeding from this it follows that children with anorectal malformations should be concentrated in specialized children's surgical departments, where they are examined, the choice of surgical treatment, post-operative treatment, dispensary supervision, and the appointment and conduct of repeated courses of rehabilitation. As seen from the study of the long-term results of the surgical treatment of atresia of the anus and rectum with vestibular and perinealectopia of the anal canal, in most of our patients (62.8\%) good anatomical and functional results were obtained. But in $29 \%$ the result was assessed as satisfactory and in $8.2 \%$ - unsatisfactory, in absolute figures it looks like this: good results - in 54 , satisfactory - in 25 , unsatisfactory - in 7. Among children with satisfactory results, 3 groups were identified: children of the first group (13) have permanent constipation, in children the second (10) - calomization, in the third group (2) - constipation and calomization. All these children need permanent rehabilitation activities that differ in nature.

\section{Conclusion}

Thus, children with permanent constipation are given food containing a large amount of fiber (fruits, vegetables, bread from whole meal bread), inside daily- Vaseline oil in the age-related dosage 3 times a day, at the same time cleansing hypertension enemas are made, bougie with the finger of the anal opening.

Thus, for surgical treatment of anorectal malformation, a significant number of operations have been proposed, in which, unfortunately, the possible variants of pathological disorders are not always taken into account. Therefore, some of the operations performed are inadequate, which forces surgeons to perform repeated interventions after the failure of rehabilitation therapy. However, repeated and reconstructive operations should be treated very cautiously due to the fact that anal retention can significantly improve with the development and growth of the child. Rehabilitation measures are shown to all children at all stages of treatment.

\section{References}

1. Isakov Yu F, Stepanov EA, Smirnov AN (2000) surgical treatment of fecal incontinence in children, Surgery M 4: S45-48.

2. Karimov U Sh, Lonyushkin AI (2007) Post-operative bowel dysfunction and their possible correction in children with anorectalanomalies. Questions modern pediatric (2).

3. Nikiforov AN, Averin VI, Degtyarev Yu G (2005) Rehabilitation of children with anorectal malformations. Medical Journal: peer-reviewed scientific and practical journal 4: 82-85.

4. Schitinin VE, Podmarenkova LF (2001) Analysis of the separated results of surgical treatment of anorectal malformations in girls. Surgery M 11: S51-54. 
5. Lenyushkin AI (1999) Surgical Coloproctology of Childhood. M "Medicine" pp. 368.

6. Prokurat A, Chruper M, Kaminski W (1998) the internal sphincter muscle in fistula is manometric studies of the external visible fistula in girls with low and intermediate anorectal malformations. Child Intern 3: $148-152$.
(C) (1) This work is licensed under Creative

To Submit Your Article Click Here: Submit Article

DOI: 10.32474/PAPN.2018.01.000113

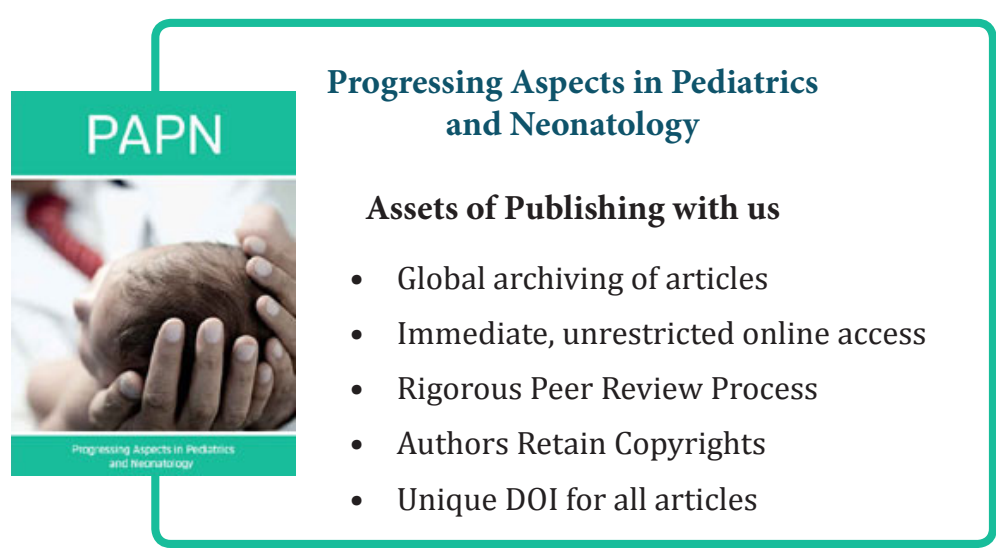

